Max-Planck-Institut für demografische Forschung

Max Planck Institute for Demographic Research

Konrad-Zuse-Strasse 1 - D-18057 Rostock - GERMANY

Tel +49 (0) 3812081 - 0; Fax +49 (0) 3812081 - 202;

http://www.demogr.mpg.de

MPIDR WORKING PAPER WP 2011-009

JUNE 2011

\title{
Maternal Age and Offspring Adult Health: Evidence from the Health and Retirement Study
}

Mikko Myrskylä (myrskyla@demogr.mpg.de)

Andrew Fenelon

(C) Copyright is held by the authors.

Working papers of the Max Planck Institute for Demographic Research receive only limited review. Views or opinions expressed in working papers are attributable to the authors and do not necessarily reflect those of the Institute. 
Maternal Age and Offspring Adult Health: Evidence from the Health and Retirement Study

Mikko Myrskylä [1]

Andrew Fenelon [2]

[1] Research group Life Course Dynamics and Demographic Change, Max Planck Institute for Demographic Research. Email myrskyla@demogr.mpg.de. Address: Max Planck Institute for Demographic Research, Konrad-Zuse-Str. 1, 18057 Rostock, Germany

[2] Population Studies Center and Department of Sociology, University of Pennsylvania, Philadelphia, PA 


\begin{abstract}
Advanced maternal age is associated with negative offspring health outcomes. The interpretation often relies on physiological processes related to aging, such as decreasing oocyte quality. We use a large population-based sample of American adults to analyze how selection and lifespan overlap between generations influence the maternal age-offspring adult health association. We find that offspring born to mothers below age 25 or above 35 have worse outcomes with respect to mortality, self-rated health, height, obesity and the number of diagnosed conditions than those born to mothers aged 25-34. Controls for maternal education and age at which the child lost the mother eliminate the effect for advanced maternal age up to age 45 . The association between young maternal age and negative offspring outcomes is robust to these controls. Our findings suggest that the advanced maternal age-offspring adult health association reflects selection and factors related to lifespan overlap. These may include shared frailty or parental investment, but are not directly related to the physiological health of the mother during conception, fetal development, or birth. The results for young maternal age add to the evidence suggesting that children born to young mothers might be better off if the parents waited a few years.
\end{abstract}




\section{INTRODUCTION}

A hundred years ago Alexander Graham Bell suggested that children born to young mothers have the longest lifespan, and children born to older mothers have the shortest (Bell 1918). Since Bell, Lansing $(1947 ; 1948)$ and others have demonstrated that the negative advanced parental age-offspring health association exists also among a wide range of non-human organisms, including rotifers, fruit flies, and yeast (for a review, see Priest, Mackowiak and Promislow 2002). For humans, evidence on the negative association between advanced maternal age (mother aged 35 or more at the time of birth) and offspring health has been accumulating in recent years (Jacobsson, Ladfors and Milsom 2004; Liu, Zhi and Li 2011; Nassar and Usta 2009; Tarín, Brines and Cano 1998). While some find little or no evidence for the link between advanced maternal age and offspring adult health and mortality (Hubbard, Andrew and Rockwood 2009; Robine et al. 2003; Westendorp and Kirkwood 2001), the majority of studies suggest that advanced maternal age is associated with a range of negative child and adult health outcomes including Alzheimer's disease (Rocca et al. 1991), hypertension (Brion et al. 2008), diabetes (Gale 2010), cancer (Hemminki and Kyyrönen 1999; Johnson et al. 2009), and mortality (Kemkes-Grottenthaler 2004).

Discussion of the mechanisms behind the advanced maternal age-offspring health association is dominated by physio-biological interpretations which stress the importance of the health of the mother and her reproductive system during conception, fetal development, and birth (Armstrong 2001; Durkin et al. 2008; Fang et al. 2008; Gale 2010; Johnson et al. 2009; Kemkes-Grottenthaler 2004; Menezes et al. 2010; Rocca et al. 1991). Socioeconomic selection and differentials in the age at which the child loses the mother have received considerably less attention. These, however, may be integral to the maternal age-offspring health association. 
First, childhood socioeconomic status is associated with adult health (Hayward and Gorman 2004; Strand and Kunst 2007). If maternal age correlates with childhood socioeconomic status, social selection may explain some of the maternal age-adult health link. Second, the age at which a child loses the mother is systematically related to maternal age: other things being equal, a child born to a mother aged 40 can expect to lose the mother at twenty years younger age than a child born to a mother aged 20. Parental loss at a young age may influence a range of later-life outcomes from education to health and longevity (Case, Paxson and Ableidinger 2004; van Poppel 2000).

We use a large population-based sample of American adults to analyze the roles of selection by socioeconomic status and lifespan overlap between the mother and the child in the maternal age-offspring adult health association. Consistent with prior literature, we find that children born to young and old mothers have worse adult health, are shorter, and have higher mortality than those born to mothers aged 25-35 years. Controls for maternal education and lifespan overlap wipe out the effect for advanced maternal age up to age 45 . The association between young maternal age and negative offspring outcomes, however, is robust to these controls. Our findings suggest that up to maternal age 45, the maternal age-offspring association is attributable to selection and factors proxied by age at which the child loses the mother. These may include within-family frailty, or decreases in parental investment. The physiological health status of the mother, however, seems to matter only insofar as it predicts the age at which the child loses the mother, but does not appear to directly impact the health experience of the child at adult ages. Our results on young maternal age add to the evidence suggesting that children born to a young mother might be better off if the prospective parents waited a few years. 


\section{Importance}

Prior research suggests that the effects of advanced maternal age on offspring health are potentially large. Bell (1918) analyzed the descendants of William Hyde, an early settler in Connecticut in the $17^{\text {th }}$ century, and found that those born to mothers aged 40 and above had 10.6 years shorter life expectancy than those born to mothers below age 25. Jalavisto (1959) analyzed $17^{\text {th }}-19^{\text {th }}$ century Finnish and Swedish families and found maternal age above 40 to be associated with 5 years shorter life expectancy than maternal age below 25. KemkesGrottenthaler (2004) found a similar difference in an analysis of $17^{\text {th }}-20^{\text {th }}$ century German data. Gavrilov and colleagues (1997) studied Russian nobility from the $18^{\text {th }}-19^{\text {th }}$ centuries and found that daughters born to mothers aged above 40 had 3.6 years shorter remaining life expectancy at age 30 than daughters born to mothers aged below 40. Analyses of European aristocracy, however, found only weak association between advanced maternal age and offspring longevity (Gavrilov et al. 2000). ${ }^{1}$ Smith et al. (2009) analyzed Utah cohorts born in 1850-1900 and found that compared to maternal age 20-29, maternal age above 35 is associated with $8 \%$ increased adult mortality for sons.

The advanced maternal age-offspring health association applies not only to all-cause mortality but also to specific medical conditions. Hemminki and Kyyrinen (1999) found that maternal age above 35 was associated with 50\% excess risk for leukemia. Yip et al. (2006) reported childhood retinoblastoma to have incidence rate ratio 2.39 for maternal age above 40

\footnotetext{
${ }^{1}$ Gavrilov and Gavrilova (2000) and others (for a review see Liu 2011) have found evidence that advanced paternal age may also be linked with offspring health. We focus on maternal age. However, as paternal age correlates with maternal age (Ni Bhrolchain 2001), paternal age may confound the maternal age-offspring health association. Sensitivity analyses confirmed that our results are robust to controls for paternal age.
} 
versus maternal age below 25, and Johnson et al. (2009) found that childhood cancer risk increases by $8 \%$ for every 5 year increase in maternal age, Advanced maternal age has also been linked with autism (Durkin et al. 2008), bipolar affective disorder (Menezes et al. 2010), Alzheimer's disease (Rocca et al. 1991), hypertension (Brion et al. 2008), and diabetes (Gale 2010).

These associations have prompted some to ask 'how old is too old?'(Heffner 2004). It has been suggested that people should be better informed about the risks associated with advanced maternal age (Benzies 2008). Indeed, as fertility is being postponed into ever higher ages (Billari et al. 2007; Frejka and Sobotka 2009) the maternal age-offspring health association may become a public health concern, in particular if the link is causal.

\section{Mechanisms}

Our main interest is in advanced maternal age effect and its determinants. While young maternal age is also associated with negative offspring health (D'Onofrio et al. 2009; Fraser, Brockert and Ward 1995; Geronimus and Korenman 1992; Levine, Emery and Pollack 2007; Scholl et al. 1992), the mechanism that produces the association for young mothers may be different from the mechanism behind the association for older mothers. Thus we discuss young maternal age only briefly and concentrate on advanced maternal age.

The mechanisms thought to be responsible for the young maternal age-offspring health link are related to physiological immaturity and sociodemographic disadvantage that often accompanies young parenthood (Fraser et al. 1995). Some of the young maternal ageoffspring health association may be due to selection (Geronimus and Korneman 1992), but there is no consensus on this (D’Onofrio et al. 2009). On the other hand, the negative association between advanced maternal age and adult health is thought to be driven by the physiological aging of the mother. As the female body ages, physio-biological functioning 
which is critical for a healthy conception, fetal development, low-risk birth, and post-birth development deteriorates. This deterioration may result in compromised birth outcomes or suboptimal post-birth development. Two potential alternative mechanisms are unobserved selection by maternal characteristics and differentials in intergenerational transfers by maternal age. We discuss each of these below.

Maternal age and aging. Delayed motherhood is characterized by increased probability of obstetric complications and perinatal problems (Tarín et al. 1998). These problems are largely related to declining fecundity, which has long been recognized in demographic and epidemiological literature (Heffner 2004; Leridon 2004; Menken, Trussell and Larsen 1986). For women, fecundity decline and the probability of adverse pregnancy outcomes begin to increase in late 20s-early 30s (American Society for Reproductive Medicine 2003; van Noord-Zaadstra et al. 1991). The biological mechanisms responsible for the fecundity decline are related to accumulation of DNA damage in germ cells (Kaytor et al. 1997); decreasing oocyte quality (Armstrong 2001; Eichenlaub-Ritter 1998); and weakening of the placenta (Bottini et al. 2001). These processes relate to a wide array of negative birth outcomes, including chromosomal abnormalities and birth defects.

Maternal aging may promote the development of conditions in adulthood by impacting the early life conditions of the offspring. DNA damage in germ cells, chromosomal changes, and pregnancy complications which increase with age have been suggested as causing the association between advanced maternal age and schizophrenia and Alzheimer's disease (Croen et al. 2007; Durkin et al. 2008; Menezes et al. 2010) and cancer (Johnson et al.2009). Alternatively, aging-induced changes in hormonal levels or other physiological parameters that modify the intrauterine environment may influence offspring health, such as risk of cancer (Ekbom et al. 1997; Johnson et al. 2009). 
Advanced maternal age may also be positively linked with offspring health. Birth weight increases with maternal age (Fessler et al. 2005), and low birth weight predicts adult diseases such as coronary artery disease and diabetes (Barker 2002). The detrimental effect of higher germ cell damage of older parents may be offset by the increased longevity of those able to bear children later in life. Finally, older parents may have access to greater resources and higher socioeconomic status, which are linked to improved offspring health.

Alternative mechanisms. For many of the health outcomes discussed above, evidence for the aging related mechanism that might cause the maternal age-offspring outcomes link is largely speculative. In addition to the aging related mechanisms, one should acknowledge the potential role of alternative, non-aging related mechanisms. These include selection (women who have children at certain ages may be different from those who have children at other ages), changing resources (those who have children later may have accumulated more resources than those who have children earlier), differentials in parental investment, and shared frailty. While these explanations are occasionally mentioned, their contribution to the maternal age-offspring health association has not been subject to much direct analysis. We point to two particularly important factors: parental socioeconomic status and age at which the child loses the parents. Both factors are potential confounders as they are likely to be correlated with both parental age and offspring health.

Childhood socioeconomic status is strongly associated with adult health and mortality (Galobardes, Lynch and Davey Smith 2004; Hayward and Gorman 2004; Strand and Kunst 2007). The mechanisms through which childhood social environment influences adult health may be direct, operating through childhood health, or indirect, operating through adult characteristics such as attained socioeconomic status and health behaviors (Preston, Hill and Drevenstedt 1998). Independent of the mechanism, if maternal age correlates with childhood 
socioeconomic status, social selection may explain some of the maternal age-adult health link. Currently, older parents are often more affluent and have higher educational attainment than younger parents (Bray, Gunnell and Davey Smith 2006). These socioeconomic differences influence health in childhood and adulthood so that those born to young, often socially deprived mothers have worse health outcomes than those born to older mothers (Bradley, Cupples and Irvine 2002). There is, however, no evidence that advanced parental age was positively associated with socioeconomic status in historical periods, or in the first half of the $20^{\text {th }}$ century when participants of this and many other studies on parental age effects were born.

The age at which the child loses the parent, in turn, is systematically related to parental age: holding other factors constant, a child born to a mother aged 20 will on average lose the mother at an age 20 years older than a child that is born to a mother aged 40 . The age at which the child loses the parent may proxy shared family frailty. Long-lived parents have long-lived children, and if long-lived parents have children at older ager, this may influence the association. Additionally, children who lose their parents at a younger age may be scarred by the psychological shock associated with parental loss, or they may receive less parental investment than their counterparts with greater lifespan overlap. As a result, these individuals may have lower socioeconomic attainment and worse health at adult ages (Andersson, Hogberg and Åkerman 1996; Case et al. 2004; van Poppel 2000). Thus, having an older parent may be more a socioeconomic liability than a physiological one. 


\section{METHODS}

\section{Participants}

This is a prospective cohort study. We use the Health and Retirement Study (HRS), a nationally representative panel survey of Americans aged 50 and over and their spouses. The HRS has five entry cohorts with follow-up: the initial HRS cohort, born in 1931-1941 and entering the study in 1992; the Children of Depression cohort, born in 1924-1930 and entering in 1998; and the War Babies cohort, born in 1942-1947 and entering in 1998, the Early Baby Boomer cohort, born 1948-1953 and entering in 2004, and the Assets and Health Dynamics Among the Oldest Old cohort, born before 1924 and entering in 1993. We use these HRS cohorts and include in our analytical sample persons who were aged 40 or more when entering the study. Follow-up is until 2008. The initial sample size is 30,294 persons. After exclusion of subjects with missing data on maternal age $(10,881$ persons) or other variables (1,078 persons), our sample size is 18,335 subjects with average age 56.3 years at first interview and 3,142 deaths over an average follow-up of 11.2 years.

\section{Variables}

Dependent variables. We analyze all-cause mortality and four non-fatal health outcomes: obesity, height, self-rated health, and a frailty index defined as the cumulative sum of eight diagnosed conditions. All measurements except mortality are based on the first interview.

For mortality, survival time is measured from the first interview. Month and year of death are obtained from the National Death Index. Height is measured in centimeters. Obesity is measured using an indicator equal to 1 if body mass index (BMI, defined as $\mathrm{kg} / \mathrm{m}^{2}$ ) is 30 or more, and 0 otherwise. Both height and weight are based on self-reports. Self-rated health is 
reported as excellent, very good, good, fair or poor. We code these to a 5 point continuous variable with $1=$ excellent and $5=$ poor.

We conceptualize frailty as a result of multiple interacting factors and define the frailty index as a cumulative sum of eight diagnosed conditions. These are based on self-reports to questions of the type: "Has a doctor ever told you that you have [the condition]" The conditions of which HRS has information are high blood pressure or hypertension; diabetes or high blood sugar; cancer or a malignant tumor (not skin cancer); chronic lung disease except asthma; heart attack, coronary heart disease or other heart problems; stroke or transient ischemic attack (TIA); emotional, nervous, or psychiatric problems; and arthritis or rheumatism. From these data we construct a frailty index which is the cumulative sum of diagnosed conditions, ranging from 0 to 8 .

Independent variables. The key independent variable is maternal age, defined as the age of the mother (years) at the time of the child's birth. The HRS has questions on whether the mother is alive; if yes how old the mother is; and if not when and at what age did the mother die. These combined with the survey year and birth year of the respondent allow calculating maternal age. We categorize maternal age as 14-19, 20-24, 25-34 (reference group), 35-39, 40-44 and 45-49.

Other independent variables of particular interest are maternal education and lifespan overlap between the child and the mother. Maternal education is measured with a binary indicator equal to 1 if the mother has 8 or more years of schooling, and 0 otherwise. We use this measure because some of the HRS waves have only categorical information on maternal education, and binary education was the only consistently comparable measure that could be constructed. 
Lifespan overlap between the child and the mother is measured by using an indicator equal to 1 if the mother was alive when the person was aged 40 and 0 otherwise. This indicator is crude, dividing the population into those who had their mother alive when they were aged 40 and those who had lost their mother at a younger age. We prefer this measure over a continuous measure of the number of years children overlap with their mothers because of its simplicity and to avoid problems of censoring for those children with live mothers. We show that the results are robust to alternative, more nuanced specifications of lifespan overlap in the Sensitivity Analyses section.

We control for lifespan overlap for two reasons. First, lifespan overlap is systematically and negatively related to maternal age, as discussed above. Second, lifespan overlap may be related to offspring health through numerous mechanisms. Lifespan overlap may capture differences in intergenerational social and economic transfers that result from differences in the age at which the child lost the parent. Lifespan overlap may also capture age-related differences in the effect of the psychological shock that is related to parental loss. In addition, lifespan overlap may implicitly reflect differences in general maternal health, insofar as they are reflected in the years that the parent lives after the birth of the child. Finally, lifespan overlap may capture differences in familial longevity, which may have genetic, epigenetic or behavioral roots.

Optimally one would measure each of these mechanisms directly, but lack of data prevents us from doing so. However, controlling for lifespan overlap helps to elucidate whether the impact of parental age of offspring health is due to the physiological health of parental reproductive systems at and around the time of birth, or due to alternative factors that operate later in life. In addition, we are able to shed light on the importance of the intergenerational transfers mechanism by including as control variables the person's own socioeconomic 
attainment, measured by education (less than high shool, high school, some college, bachelor's degree or higher) and household income (logged). If lifespan overlap influences the maternal age-offspring health association through intergenerational transfers, controls for respondent socioeconomic status should attenuate the size and significance of the regression coefficient for lifespan overlap. If lifespan overlap reflects other factors such as within-family frailty, the importance of lifespan overlap should be robust to these controls.

Other independent variables are birth year, age and age squared at baseline (years), sex, and race/ethnicity (white, black, other).

\section{Statistical models}

We estimate five different models for each health outcome. The following set of equations illustrates the hierarchy of the models by using self-rated health as the model outcome variable:

(1) $Y=\alpha+\boldsymbol{\beta}_{1} \mathbf{M A B}+\boldsymbol{\beta}_{2} \mathbf{D E M}+\varepsilon$

(2) $Y=\alpha+\boldsymbol{\beta}_{1} \mathbf{M A B}+\boldsymbol{\beta}_{2} \mathbf{D E M}+\beta_{3} M a t E d u+\varepsilon$

(3) $Y=\alpha+\boldsymbol{\beta}_{1} \mathbf{M A B}+\boldsymbol{\beta}_{2} \mathbf{D E M}+\beta_{4}$ Overlap $+\varepsilon$

(4) $Y=\alpha+\boldsymbol{\beta}_{1} \mathbf{M A B}+\boldsymbol{\beta}_{2}$ DEM $+\beta_{3}$ MatEdu $+\beta_{4}$ Overlap $+\varepsilon$

(5) $Y=\alpha+\boldsymbol{\beta}_{1} \mathbf{M A B}+\boldsymbol{\beta}_{2}$ DEM $+\beta_{3}$ MatEdu $+\beta_{4}$ Overlap $+\boldsymbol{\beta}_{5} \mathbf{S E S}+\varepsilon$,

where $Y$ is the health outcome; MAB is the vector of maternal age; DEM is the vector of demographic characteristics (birth year, age and age squared, sex, race/ethnicity); MatEdu is the indicator for maternal education; Overlap is the indicator for lifespan overlap (mother 
alive/dead when ego 40); and SES is the vector of person's own education and logged household income.

Model 1 estimates the association between maternal age and health and adjusts for basic demographic variables. Model 2 adds maternal education as a control variable to Model 1. Comparing Models 1 and 2 demonstrates the confounding influence of maternal education in the maternal age-offspring health association.

Model 3 adds lifespan overlap with the mother to Model 1. Comparing the results between Models 1 and 3 reveals the confounding influence of lifespan overlap in the maternal ageoffspring health association.

Model 4 simultaneously adds maternal education and lifespan overlap with the mother to Model 1. Comparing the results between Model 1 and Model 4 shows the joint confounding influence of education and lifespan overlap in the maternal age-offspring health association.

Model 5 adds controls for adult socioeconomic status. Comparing the lifespan overlap coefficient in Models 4 and 5 helps understand the pathways through which lifespan overlap influences the maternal age-offspring health association. Since own socioeconomic status is on the pathway from maternal age to offspring health, interpretation of the maternal age coefficient must be cautious in Model 5.

We estimate the Models 1-5 for the five health outcomes using four model specifications. For self-rated health and height we use the ordinary linear regression model. For the count variable frailty we use the negative binomial regression since the data exhibited overdispersion. For obesity we use a logistic model. For all-cause mortality we use a Cox proportional hazards model. All models account for the households clustering of subjects by using a robust variance-covariance estimator. In the Cox model, we use time-on-study for 
time scale and adjust for age and age squared; this approach performed well in a study comparing six different choices of time scale in cohort studies (Pencina, Larson and D'Agostino 2007). We handle ties with the Breslow method. We checked the proportional hazards assumption for maternal age by testing the significance of the interaction terms with the log of follow-up time. The tests did not indicate deviations from proportionality. 


\section{RESULTS}

\section{Descriptive analyses}

Table 1 shows the sample characteristics. Advanced maternal age is relatively rare, as only $12 \%$ have maternal age 35 or above. Young maternal age is more common as $16.6 \%$ have maternal age below 20. The respondents are born on average in 1939-40, and there is little variation in birth year by maternal age. Those with oldest mothers are slightly older than those with younger mothers: at first interview, mean age is 57.1 years for those with maternal age 40-44 and 56.1 years for those with maternal age 25-34. Proportion of women is approximately $60 \%$ in all maternal age groups except among those with maternal age 45-49 where only $49 \%$ are women. This difference is not statistically significant ( $\left.\mathrm{p}^{>} .05\right)$ and may reflect small sample variation.

\section{TABLE 1 ABOUT HERE}

Mean follow-up is 8.2 years for those who died and 11.8 for the censored. The proportion who died during the follow-up is highest for young and old maternal age, and lowest in the maternal age group 25-34. Frailty index, self-rated health, proportion obese and height exhibit a similar U-shaped pattern: the health outcomes are worst for those born to young or old mothers, and best for those born to mothers aged 25-34.

The independent variables show that there is a U-shape (inverted) association also in maternal education, which is lowest among those with young or old mother and highest among those with maternal age 20-34. Lifespan overlap, in turn, decreases almost monotonically with maternal age. Over $50 \%$ of those with maternal age above 40 have lost their mother by the time they themselves were 40 years old. Among those with maternal age below 35, it was only $20 \%$. Own socioeconomic characteristics show a similar pattern to we 
observed for health outcomes. Those born to mothers aged 25-34 have higher household income and are more likely to have college education than those born to older or younger mothers.

In summary, mother's education, lifespan overlap, and socioeconomic outcomes are associated with maternal age, highlighting the importance of adjusting for these characteristics in the maternal age-offspring health analysis.

\section{Regression analyses}

Tables 2-6 show results from the multivariate analyses. Table 2 is for the Frailty index, Table 3 for self-rated health, Table 4 for height, Table 5 for obesity and Table 6 for mortality. Figure 1 Panels A-E illustrate the results. In Figure 1, we have used a semiparametric regression model (Lokshin 2006) which imposes no shape on the dependent variablematernal age association (non-parametric part) while controlling for other independent variables as in normal regression (the parametric part).

\section{FIGURE 1 ABOUT HERE}

\section{TABLES 2-7 ABOUT HERE}

Frailty. Table 2 shows the association between the frailty index and maternal age. Model 1 estimates the association while controlling for basic demographic characteristics; Model 2 adds maternal education to Model 1; Model 3 adds maternal lifespan overlap to Model 1; Model 4 adds simultaneously maternal education and maternal lifespan overlap to Model 4; and Model 5 adds own socioeconomic attainment to Model 4.

Model 1 shows that there is a strong U-shaped association between maternal age and frailty index. Compared to maternal age 25-34, those with maternal age 14-19 have $0.131(\mathrm{p}<.001)$ 
more health conditions, and those with maternal ages 35-39, 40-44 and 45-49 have 0.093 $(\mathrm{p}<.001), 0.108(\mathrm{p}<.05)$ and $0.223(\mathrm{p}<.01)$ more health conditions, respectively. The coefficients for the control variables are in the expected direction. Figure 1 Panel A illustrates how frailty index starts to increase at maternal age about 30 for Model 1.

Model 2 adds controls for maternal education. The effects associated with young maternal age $(<25)$ are virtually unchanged, while those associated with advanced maternal age are slightly attenuated, but stay statistically and substantively significant. Unsurprisingly, those whose mother had 8 or more years of schooling have less conditions than those with less educated mothers.

Model 3 adds controls for lifespan overlap to Model 1. The effects associated with young maternal age are marginally strengthened, but those associated with advanced maternal age are markedly attenuated. The coefficient for lifespan overlap shows that those whose mother was alive when they were aged 40 had $0.158(\mathrm{p}<0.001)$ fewer diagnosed conditions than those whose mother had died.

Model 4 controls simultaneously for maternal education and lifespan overlap. The negative effects associated with young maternal age are robust to these controls. The effects associated with advanced maternal age, however, are attenuated to a point where they lose statistical significance. Those born to mothers aged 35-39 and 40-44 have $0.05(p=.22)$ and 0.04 $(p=.62)$ more health conditions than those born to mothers aged 25-34. These are statistically and substantively negligible differences. The effect associated with maternal age 45-49 stays at 0.12 but loses significance. Figure 1 Panel A illustrates how the frailty index increases only little before maternal age 45 once maternal education and lifespan overlap are controlled (Model 4), whereas the young maternal age effect is robust to these adjustments. 
Model 5 adds own socioeconomic attainment to Model 4. These controls attenuate slightly the coefficients for young maternal age, but do not affect the advanced maternal age coefficients. Maternal education, however, loses all predictive power, suggesting that maternal education influences health and confounds the maternal age-offspring health association through offspring socioeconomic attainment. Lifespan overlap is more robust to controls for own socioeconomic attainment, decreasing by only $11 \%$ from -0.149 to -0.132 . This suggests that the mechanism through which lifespan overlap is associated with offspring health only partially reflects intergenerational transmission of economic and social resources.

Self-rated health. Table 3 shows the results for self-rated health; Figure 1 Panel B illustrates the results with semiparametric regression. The patterns are highly similar to those of frailty. Model 1 shows that those born to mothers aged less than 25 or above 35 have worse selfrated health than those born to mothers aged 25-34. Controlling for maternal education (Model 2) or lifespan overlap (Model 3) slightly strengthens the effects for young maternal age and attenuates the effects for advanced maternal age but does not alter the overall Ushaped pattern. Controlling simultaneously for maternal education and lifespan overlap (Model 4) attenuates the effects for advanced maternal age up to age 45 to a level that is uninteresting both statistically and substantively. The coefficient for maternal age 45-49 stays relatively large and statistically significant $(\mathrm{p}<.05)$.

Controls for own socioeconomic status (Model 5) attenuate the maternal age coefficients that remained significant in Model 4 (ages below 25 and above 45) by 40-50\%, suggesting that young and very old maternal ages are associated with self-rated heath through socioeconomic status. Maternal education is attenuated by $61 \%$ but lifespan overlap by only $25 \%$. As with the frailty index, lifespan overlap influences the maternal age-offspring health association only partially through socioeconomic attainment. 
Height. Table 4 shows the results for height; Figure 1 Panel C illustrates the results using semiparametric regression. Model 1 shows that those with maternal age below 25 or above 35 are shorter than those with maternal age 25-34. Controlling for maternal education (Model 2) or lifespan overlap (Model 3) does not change the associations for young maternal age. Controlling for maternal education removes the effects associated with advanced maternal age, but controlling for lifespan overlap does not. Simultaneous controls for maternal education and lifespan overlap (Model 4) has little impact on young maternal age coefficients, but those for advanced maternal age decrease to a statistically insignificant level.

Controls for own socioeconomic status (Model 5) have little impact on maternal age coefficients, but attenuate the maternal education coefficient by $36 \%$. This is less than what was observed for frailty and self-rated health since height is determined at an early age, making it unlikely that maternal education influenced height through socioeconomic attainment. The coefficient for lifespan overlap is attenuated by $22 \%$, which is comparable to the attenuation seen for frailty and self-rated health. The weak attenuation is expected since the time ordering of events makes it unlikely that lifespan overlap influenced height through socioeconomic attainment.

Obesity. Tables 5 shows the results for obesity; Figure 1 Panel D illustrates the results using semiparametric regression. Model 1 suggests that there is a U-shaped association between maternal age and the odds of being obese obesity, though the coefficients for ages above 40 are not significant (Model 1). Controlling for maternal education (Model 2) or lifespan overlap (Model 3) or simultaneous controlling for these factors (Model 4) strengthens the young maternal age coefficients. The associations for advanced maternal age vanish when maternal education and lifespan overlap are controlled (Model 4). Controls for 
socioeconomic status (Model 5) remove the predictive power or maternal education but, as in the previous models, attenuate the coefficient for lifespan overlap only slightly.

Mortality. Table 6 shows the results for mortality; Figure 1 Panel E illustrates the results using semiparametric regression. Model 1 suggests that there is a U-shaped pattern between maternal age and offspring mortality: those with maternal age below 20 or above 45 have significantly higher mortality than those with maternal age 25-34. The coefficients for ages 20-24 and 35-44 are consistent with the U-shaped pattern, but not always significant. Controlling for maternal education (Model 2) or lifespan overlap (Model 3) or simultaneous controlling for these factors (Model 4) strengthens the associations for young maternal age. The associations for advanced maternal age lose statistical significance ( $>$ >.05) when controls for maternal education and lifespan overlap (Model 4) are introduced. Controls for own socioeconomic status (Model 5) attenuate the associations for young maternal age. These controls also remove the effect associated with maternal education, but not lifespan overlap.

\section{Sensitivity analyses}

Our key result - no effect of advanced maternal age up to age 45 on health or mortality after controlling for maternal education and lifespan overlap - was robust to changes in the categorization of maternal age, in particular to changing the reference group to 25-29 or to combining ages 40-44 and 45-49 to increase statistical power.

The results were robust to the following alternative specifications of the dependent variables and functional forms of the regression models: frailty index excluding mental health problems or cancer; ordered logistic instead of linear specification of self-rated health; linear instead of binary obesity measure of body mass index; and logistic instead of Cox proportional hazard model for mortality with the dependent variable a binary indicator for survival (dead/alive after 10 years of follow-up). 
We studied the robustness of our results to an alternative specification of the lifespan overlap variable so that lifespan overlap was categorized to ten-year intervals and capped at 40 or more years. The results did not change in any significant manner.

We studied how paternal age might influence our results. We did not control for paternal age since this correlates strongly with maternal age, increasing multicollinearity problems, and because information on paternal age was available for less than two thirds of our sample. However, paternal age is negatively associated with health (Liu et al. 2011), thus omission of the variable may result in slight overestimation of the negative advanced maternal ageoffspring health association. Our key result is that even without controls for paternal age, the maternal age-offspring health association is weak up to maternal age 45 when maternal education and lifespan overlap are controlled for. Thus the potential bias arising from omission of paternal age strengthens our key result. Moreover, sensitivity analyses confirmed that our results hold when the analyses are replicated for a subset for which paternal age is available and controlled for.

We had limited information on birth order. For the 18,335 subjects in our data, only 6,738 had information on birth order. Analyses for this subset with controls for birth order did not change our results: net of maternal education and lifespan overlap, young maternal age $(<25)$ continued to be associated with adverse health outcomes, but advanced maternal age up to age 45 was not.

Our results were similar for both men and women. We estimated all models with maternal age-sex interactions, and these were not statistically significant ( $\mathrm{p}>.05)$ for any of the outcomes. 


\section{DISCUSSION}

Expanding literature documents that advanced maternal age is associated with negative offspring health outcomes. The interpretation often relies on physiological processes related to aging, such as decreasing quality of the placenta or oocytes. We used a large population based sample to analyze the roles of selection and lifespan overlap in the maternal ageoffspring adult health association. We find that mortality, self-rated health, height, obesity and the number of diagnosed conditions are strongly associated with maternal age: those with maternal age below 25 or above 35 have markedly worse adult health than those with maternal age 25-34. Controls for maternal education and age at which the child lost the mother eliminate the effect for advanced maternal age up to age 45. Maternal age 45-49 may be associated with negative health net of these confounders, but the small sample size precludes strong conclusions. The results suggest that maternal physio-biological health status matters for offspring health only insofar as it predicts the age at which the child loses the parents, and does not leave an imprint in the offspring which predisposes it to poor health outcomes in adulthood. The associations for young maternal age, however, are robust and strengthen as we control for maternal education and lifespan overlap.

The negative health outcomes associated with advanced maternal age can be largely explained by non-physiological maternal characteristics that are correlated with maternal age. Our results show that maternal socioeconomic status, measured by education, is a confounder in the maternal age-offspring health association. The results also show that controlling only for socioeconomic status is not enough, as the age at which the child loses the parent adds an additional layer of confounding. The age at which the parent is lost may reflect shared frailty between the child and the mother, or the amount of parental investment. 
The attenuating effects of maternal education and lifespan overlap help understand the mechanism behind the advanced maternal-offspring health association. Consider first maternal education. Childhood socioeconomic circumstances, measured by parental education, are negatively associated with adult health and mortality (Galobardes et al. 2004; Hayward and Gorman 2004; Kuh et al. 2002; Strand and Kunst 2007). Currently, old parents, especially mothers, have above average socioeconomic status and resources (Bray et al. 2006). This, however was not the case in early $20^{\text {th }}$ century America. In our nationally representative sample of U.S. adults born in the first half of the $20^{\text {th }}$ century, maternal education is inversely correlated with advanced maternal age and confounds the maternal age-offspring health association. Controlling for maternal education markedly reduces the negative association between advanced maternal age and offspring health.

Controlling for maternal education did little to attenuate the associations for young maternal age. Our control was completed education, not maternal education at birth. Had our data allowed controlling for maternal education at the time of birth, the magnitude of the young maternal age effect would most likely have been larger. Resources and parenting skills which may be correlated with maternal education - may change over the ages at which the young maternal age effect was observed, from age 14 to 25 . These changes are not reflected in the attained level of education.

Controlling for lifespan overlap with the mother in addition to maternal education reduced all the advanced maternal age effects up to age 45 to a statistically and substantively small level. The relative importance of lifespan overlap and maternal education in attenuating the advanced parental age effect depended on the outcome. For height, which is determined early, lifespan overlap mattered relatively little, and maternal education had a stronger attenuating effect. For frailty and mortality, lifespan overlap was a more important attenuator 
than maternal education. This may be because frailty and mortality are influenced by later life conditions, for which lifespan overlap may matter more than it does for outcomes that are determined very early in life.

There are several potential mechanisms through which lifespan overlap influences the maternal age-health association. First, lifespan overlap may proxy within family shared frailty, which may have genetic, epigenetic, or behavioral roots. Lifespans of mothers and their children are correlated. Long-lived mothers may also have children at older ages, so that maternal age and longevity are correlated. While it is not clear whether late reproduction increases longevity, these correlations confound the advanced maternal age-offspring health association. On the other hand, late reproduction may signal age-independent problems in fecundity, which may be correlated with general level of health. If some of these factors that produce poorer health are shared within the family, such correlations confound the maternal age-offspring health association. These shared frailty based mechanisms are not connected to the biological mechanism such as declining quality of oocytes or weakening of the placenta that are sometimes hypothesized to be responsible for the maternal age-offspring health association.

Second, lifespan overlap measures exposure to a live mother. Thus it is broadly understood as a proxy for intergenerational social and economic transfers. If the mechanism proxied by lifespan overlap is intergenerational transfers, late motherhood may have a causal effect on adult health particularly in high mortality populations where those born to older mothers are at high risk of losing their mothers at a young age. Our results, however, suggest that only a small fraction of the mechanism is attributable to such transfers, as the regression coefficient for lifespan overlap was attenuated by only $10-30 \%$ when we introduced controls for own socioeconomic status. 
Third, lifespan overlap may reflect age-related differences in the magnitude of the psychological shock that is related to parental loss. Again, this mechanism is not related to the physiological health of the parents’ reproductive systems.

Extensive analysis of the mechanism proxied by lifespan overlap was beyond the scope of this study. What is more important is that controlling for lifespan overlap markedly weakens the association between advanced maternal age and offspring health, challenging the standard interpretation for the association. In particular, controlling for lifespan overlap suggests that the association is less due to the physio-biological health of the reproductive system at and around birth and more due to alternative factors, among which within-family frailty is a candidate. Future research could focus on the mechanism through which lifespan overlap between the mother and the child influences the health outcomes.

Our results on the weak or nonexistent effect of advanced maternal age on offspring health are consistent with some recent research on maternal age effects on health. Tymicki (2009) studies $18^{\text {th }}-20^{\text {th }}$ century data Polish data and finds no association between child survival and parental age. Robine et al. (2003) finds no association between parental age and the probability of surviving to age 100 . Hubbard et al. (2009) analyze Canadian $20^{\text {th }}$ century cohorts and find no maternal age effects on health. Westendorp and Kirkwood (2001), in an analysis of British historical aristocracy, also fail to find and maternal age effects on longevity. Smith et al. (2009), however, finds that maternal age above 35 is associated with 8\% increased adult mortality for sons when compared to maternal age 20-29. The difference between our findings and the associations documented by Smith et al. may be partially due to differences in age categories. Smith et al. use age category 35 and above, which includes ages 45-49 for which we observed weak associations with health. 
Some of the seeming inconsistency between our results and the literature documenting poor health outcomes for those with advanced maternal age may be because previous studies inadequately controlled for maternal socioeconomic characteristics or lifespan overlap. There are also other mechanisms which might result in such seeming inconsistency:

First, our findings are not inconsistent with the strong evidence suggesting that advanced maternal age is associated with negative birth outcomes (Andersen et al. 2000; Cohen and Lilienfeld 1970; Misra and Ananth 2002). Adult health is characterized by complex, multidimensional etiology while negative birth outcomes such as malformations and chromosomal abnormalities more often reflect less complex disease processes. In addition, many negative birth outcomes that are associated with advanced maternal age may have only a small effect on adult population health because the conditions are rare to start with and are associated with high mortality at younger ages. For example, the incidence of Down Syndrome, the most common chromosomal abnormality, is below $1 \%$ at maternal age 40 (Hook and Lindsjö 1978), and in the 1940s when much of our sample was born, life expectancy with Down Syndrome was 12 years (Bittles et al. 2007). Low prevalence at birth and selection before eligibility to HRS likely lead to differing results from those examining early life outcomes. However, since we are interested in adult health and mortality, it would not be optimal to adjust for selection of the weakest out of our adult sample.

Second, many post-birth and adult conditions (schizophrenia, autism, bipolar affective disorder, childhood cancer) that have been linked with advanced maternal age may be too rare to have a large impact on population health. It is possible that results for specific conditions are different from general measures for health.

Third, pre-birth selection may explain some of the differences between our results for adult health, and what others have found for birth outcomes. Due to spontaneous abortions and 
stillbirths, the force of selection is strongest in utero, and increases with maternal age (Andersen and Osler 2004; de La Rochebrochard and Thonneau 2002). This maternal age dependent quality control may partially explain why health differences among adults by maternal age are small.

There are several limitations in our study. First, our follow-up starts at age 40, so we do not observe mortality selection that occurs in childhood and in early adult ages. However, since we are focusing on adult and old-age health, being able to control for such selection would not alter our findings. Second, our data does not allow us to specify what lifespan overlap proxies. This could be familial frailty, intergenerational transfers, among other things, as discussed above. Further research should provide a detailed analysis of the factors represented by lifespan overlap. One intriguing possibility would be to use within-siblings comparisons to analyze the contribution of factors that are shared within the family on the maternal age-offspring health link. Third, our controls for family socioeconomic status are rather crude, being based on a binary indicator for educational attainment. The results, however, suggest that even our crude controls perform well for the purposes of this study. Fourth, our results concern a population that was born before the widespread use of artificial reproductive technologies (ART) and prenatal screening. In contemporary world, ART help less fecund couples to reproduce, particularly at older ages. On the other hand, prenatal screening removes some of the maternal age-dependent negative birth outcomes. Both may change the future of the parental age-adult health association. Fifth, the associations we observe between advanced maternal age and offspring adult health may be a lower limit for the effect of the physiological aging of the reproductive system. Powell et al. (2006) suggest that older parents transmit more economic, cultural and social resources to their children than younger parents. These positive factors may offset some of the biological aging induced negative effects. Finally, we do not know what is causing the negative association between 
young maternal age and offspring outcomes. The robust and strong association deserves further investigation.

Thus while advanced maternal age is associated with negative early life outcomes, including increased risk of miscarriage and Down syndrome, the impact at older ages seems not to be driven by biological aging of the parents. Instead, at least in our study population which comprises of a representative sample of U.S. adults born in the first half the $20^{\text {th }}$ century, the association is driven by old parents having less education and fewer years of overlap with their children than parents aged 25-35 years. The educational difference is a pure selection effect, whereas the difference in the overlap of lives could signal many factors, including shared frailty or decreased parental investment. The majority of today's parents' lives will overlap with their offspring lives for many decades. Thus it seems unlikely that the health of the offspring of today's old parents is strongly influenced by short lifespan overlap resulting from late childbearing.

On the other hand, the results do suggest that children born to young parents might have been better off if the parents had waited a few years. The robustness of the young parent-negative offspring outcome suggests that changing parental characteristics from very young parenthood to less extreme young parenthood have beneficial effects for the offspring. Our models are unable to directly account for the factors responsible for the young parent disadvantage. The association may be related to the physiological, mental, or resource-related immaturity of the younger parents who are less able than older parents to provide their offspring necessary skills and resources.

In summary, net of some obvious confounders, only maternal ages below 25 and above 45 are associated with negative offspring health outcomes. As only $0.8 \%$ in our sample (and $1.1 \%$ in the U.S. cohorts born in 2000) have mothers aged 45 or more, the potential public 
health concern relating to the health of children with older mothers is small. Almost half of our sample (46.5\%), and 36.8\% of U.S. cohorts born in 2000 have mothers aged less than 25 years (Martin et al. 2002). The public health concern regarding maternal ages should focus on young, not old mothers. 


\section{REFERENCES}

American Society for Reproductive Medicine. 2003. Age and Fertility:A Guide for Patients. Birmingham: American Society for Reproductive Medicine.

Andersen, A.-M.N. and M. Osler. 2004. “Birth Dimensions, Parental Mortality, and Mortality in Early Adult Age: A Cohort Study of Danish Men Born in 1953.” Int. J. Epidemiol. 33(1):92-99.

Andersen, A.-M.N., J. Wohlfahrt, P. Christens, J. Olsen, and M. Melbye. 2000. "Maternal Age and Fetal Loss: Population Based Register Linkage Study." BMJ 320(7251):1708-1712.

Andersson, T., U. Hogberg, and S. Åkerman. 1996. "Survival of Orphans in 19th Century Sweden—The Importance of Remarriages." Acta Pædiatrica 85(8):981-985.

Armstrong, D.T. 2001. “Effects of Maternal Age on Oocyte Developmental Competence.” Theriogenology 55(6):1303-1322.

Barker, D.J.P. 2002. “Fetal Programming of Coronary Heart Disease.” Trends in Endocrinology and Metabolism 13(9):364-368.

Bell, A.G. 1918. “The Duration of Life and Conditions Associated with Longevity. A Study of the Hyde Geneology.” Genealogical Record Office, Washington, D.C.

Benzies, K.M. 2008. “Advanced Maternal Age: Are Decisions About the Timing of Childbearing a Failure to Understand the Risks?” Canadian Medical Association Journal 178(2):183-184.

Billari, F.C., H.-P. Kohler, G. Andersson and H. Lundstöm. 2007. “Approaching the Limit: Long-term Trends in Late and Very Late Fertility.” Population and Development Review, 33(1):149-170. 
Bittles, A.H., C. Bower, R. Hussain, and E.J. Glasson. 2007. “The Four Ages of Down Syndrome.” European Journal of Public Health 17(2):221-225.

Bottini, E., G.F. Meloni, J. MacMurray, M. Ammendola, T. Meloni, and F. Gloria-Bottini. 2001. “Maternal Age and Traits of Offspring in Humans.” Placenta 22(8-9):787-789.

Bradley, T., M.E. Cupples, and H. Irvine. 2002. “A Case Control Study of a Deprivation Triangle: Teenage Motherhood, Poor Educational Achievement and Unemployment.” Int J Adolesc Med Health 14(2):117-123.

Bray, I., D. Gunnell, and G. Davey Smith. 2006. “Advanced Paternal Age: How Old Is Too Old?” Journal of Epidemiology and Community Health 60::851-853.

Brion, M.-J.A., S.D. Leary, D.A. Lawlor, G.D. Smith, and A.R. Ness. 2008. “Modifiable Maternal Exposures and Offspring Blood Pressure: A Review of Epidemiological Studies of Maternal Age, Diet, and Smoking.” Pediatric Research 63(6):593-598

Case, A., C. Paxson, and J. Ableidinger. 2004. "Orphans in Africa: Parental Death, Poverty, and School Enrollment." Demography 41(3):483-508.

Cohen, B.H. and A.M. Lilienfeld. 1970. "The Epidemiological Study of Mongolism in Baltimore." Annals of the New York Academy of Sciences 171(2):320-327.

Croen, L.A., D.V. Najjar, B. Fireman, and J.K. Grether. 2007. “Maternal and Paternal Age and Risk of Autism Spectrum Disorders.” Archives of Pediatrics \& Adolescent Medicine 161(4):334-340.

D’Onofrio, B.M., K.L. Donahue, C.A. Coyne, C.A. Van Hulle, J.L. Rodgers, I.D. Waldman, and B.B. Lahey. 2009. “Early Maternal Age at Childbearing and Offspring Functioning 
During Adolescence: A Sibling-comparison Study of Sexual Behavior and Depression.” Behavior Genetics 39(6):647-647.

De La Rochebrochard, E. and P. Thonneau. 2002. "Paternal Age and Maternal Age Are Risk Factors for Miscarriage; Results of a Multicentre European Study.” Hum. Reprod. 17(6):1649-1656.

Durkin, M.S., M.J. Maenner, C.J. Newschaffer, L.-C. Lee, C.M. Cunniff, J.L. Daniels, R.S. Kirby, L. Leavitt, L. Miller, W. Zahorodny, and L.A. Schieve. 2008. “Advanced Parental Age and the Risk of Autism Spectrum Disorder.” Am. J. Epidemiol. 168(11):1268-1276.

Eichenlaub-Ritter, U. 1998. “Genetics of Oocyte Ageing.” Maturitas 30(2):143-169.

Ekbom, A., C.C. Hsieh, L. Lipworth, H.O. Adami, and D. Trichopoulos. 1997. "Intrauterine Environment and Breast Cancer Risk in Women: A Population-based Study.” Journal of the National Cancer Institute 89(1):71-76.

Fang, F., F. Kamel, D.P. Sandler, P. Sparen, and W. Ye. 2008. "Maternal Age, Exposure to Siblings, and Risk of Amyotrophic Lateral Sclerosis.” Am. J. Epidemiol. 167(11):1281-1286.

Fessler, D.M.T., C.D. Navarrete, W. Hopkins, and M.K. Izard. 2005. “Examining the Terminal Investment Hypothesis in Humans and Chimpanzees: Associations Among Maternal Age, Parity, and Birth.” American Journal of Physical Anthropology 127(1):95-104.

Fraser, A.M., J.E. Brockert, and R.H. Ward. 1995. “Association of Young Maternal Age with Adverse Reproductive Outcomes.” New England Journal of Medicine 332(17):1113-1117.

Frejka, T. and T. Sobotka. 2009. “Chapter 1: Fertility in Europe: Diverse, Delayed and Below Replacement.” In Childbearing Trends and Policies in Europe, edited by T. Frejka, T. Sobotka, and J. Hoem. 
Gale, E.A.M. 2010. “Maternal Age and Diabetes in Childhood.” BMJ 340:c623.

Galobardes, B., J.W. Lynch, and G. Davey Smith. 2004. "Childhood Socioeconomic Circumstances and Cause-specific Mortality in Adulthood: Systematic Review and Interpretation." Epidemiologic Reviews 26:7-21.

Gavrilov L.A., Gavrilova N.S., Semyonova V.G., Evdokushkina G.N., Kroutko V.N., Gavrilova A.L., Evdokushkina N.N., Lapshin E.V. 1997. “Maternal Age and Offspring Longevity.” Proc. Russian Acad. Sci. [Doklady Akademii Nauk], 1997, 354(4): 569-572. English translation published in Doklady Biological Sciences, 1997, 354(4): 287-289.

Gavrilov, L.A.and N.S. Gavrilova. 2000. "Human Longevity and Parental Age at Conception." Pp. 7-31 in Sex and Longevity: Sexuality, Gender, Reproduction, Parenthood, edited by J.-M. Robine, T.B.L. Kirkwood, and M. Allard. Berlin, Heidelberg: SpringerVerlag.

Geronimus, A.T. and S. Korenman. 1992. “The Socioeconomic Consequences of Teen Childbearing Reconsidered.” Quarterly Journal of Economics 107(4):1187-1214.

Hayward, M.D. and B.K. Gorman. 2004. "The Long Arm of Childhood: The Influence of Early-life Social Conditions on Men's Mortality." Demography 41(1):87-107.

Heffner, L.J. 2004. “Advanced Maternal Age: How Old Is Too Old?” New England Journal of Medicine 351(19):1927-1929.

Hemminki, K.and P. Kyyrönen. 1999. "Parental Age and Risk of Sporadic and Familial Cancer in Offspring: Implications for Germ Cell Mutagenesis.” Epidemiology 10(6):747-751. 
Hook, E.B. and A. Lindsjö. 1978. “Down syndrome in Live Births by Single Year Maternal Age Interval in a Swedish Study: Comparison with Results from a New York State Study.” American Journal of Human Genetics 30(1):19-27.

Hubbard, R.E., M.K. Andrew, and K. Rockwood. 2009. “Effect of Parental Age at Birth on the Accumulation of Deficits, Frailty and Survival in Older Adults.” Age Ageing 38(4):380385.

Jacobsson, B., L. Ladfors, and I. Milsom. 2004. “Advanced Maternal Age and Adverse Perinatal Outcome.” Obstetrics \& Gynecology 104(4):727-733

Jalavisto, E. 1959. 1959. “Parental Age Effects in Man.” In The Lifespan of Animals (G. E. Wolstenholme and C. M. O'Connor, eds.), Ciba Foundation Colloq. on Ageing, Vol. 5, pp. 21-31. Little, Brown \& Company, Boston.

Johnson, K.J., S.E. Carozza, E.J. Chow, E.E. Fox, S. Horel, C.C. McLaughlin, B.A. Mueller, S.E. Puumala, P. Reynolds, J. Von Behren, and L.G. Spector. 2009. “Parental Age and Risk of Childhood Cancer: A Pooled Analysis.” Epidemiology 20(4):475-483

Kaytor, M.D., E.N. Burright, L.A. Duvick, H.Y. Zoghbi, and H.T. Orr. 1997. “Increased Trinucleotide Repeat Instability with Advanced Maternal Age.” Human Molecular Genetics 6(12):2135-2139.

Kemkes-Grottenthaler, A. 2004. "Parental Effects on Offspring Longevity_Evidence from 17th to 19th Century Reproductive Histories.” Annals of Human Biology 31(2):139-158.

Kuh, D., H. Rebecca, C. Langenberg, M. Richards, and M.E.J. Wadsworth. 2002. "Mortality in Adults Aged 26-54 Years Related to Socioeconomic Conditions in Childhood and Adulthood: Post War Birth Cohort Study." BMJ 325(7372):1076-1080. 
Lansing, A.I. 1947. “A Transmissible, Cumulative and Reversible Factor in Aging.” J. Gerontol. 2:228-239.

—. 1948. "Evidence for Aging as a Consequence of Growth Cessation.” Proceedings of the National Academy of Sciences 34:304-310.

Leridon, H. 2004. “Can Assisted Reproduction Technology Compensate for the Natural Decline in Fertility with Age? A Model Assessment.” Human Reproduction 19(7):15481553.

Levine, J.A., C.R. Emery, and H. Pollack. 2007. “The Well-being of Children Born to Teen Mothers.” Journal of Marriage and the Family 69(1):105-122.

Liu, Y., M. Zhi, and X. Li. 2011. "Parental Age and Characteristics of the Offspring." Ageing Res Rev 10(1):115-123.

Lokshin, M. 2006. “Difference-based Semiparametric Estimation of Partial Linear Regression Models.” Stata Journal 6(3):377-383.

Martin, J.A., B.E. Hamilton, S.J. Venture, F. Menacker, and M.M. Park. 2002. "Births: Final Data for 2000.” National Vital Statistics Reports 50(5).

Menezes, P.R., G. Lewis, et al. 2010. "Paternal and Maternal Ages at Conception and Risk of Bipolar Affective Disorder in Their Offspring.” Psychological Medicine 40(03 ):477-485.

Menken, J., J. Trussell, and U. Larsen. 1986. “Age and Infertility.” Science 233(4771):13891394.

Misra, D.P. and C.V. Ananth. 2002. "Infant Mortality Among Singletons and Twins in the United States During 2 Decades: Effects of Maternal Age." Pediatrics 110(6 I):1163-1168. 
Nassar, A.H. and I.M. Usta. 2009. “Advanced Maternal Age. Part II: Long-Term

Consequences.” Amer J Perinatol 26(02):107-112.

Ní Bhrolcháin, M. 2001. "Flexibility in the Marriage Market." Population - An English Selection 13(2):9-47.

Pencina, M.J., M.G. Larson, and R.B. D’Agostino. 2007. “Choice of Time Scale and its Effect on Significance of Predictors in Longitudinal Studies.” Statistics in Medicine 26(6):1343-1359.

Powell, B., L.C. Steelman, and R.M. Carini. 2006. "Advancing Age, Advantaged Youth: Parental Age and the Transmission of Resources to Children." Social Forces 84(3):13591390.

Preston, S.H., M.E. Hill, and G.L. Drevenstedt. 1998. "Childhood Conditions that Predict Survival to Advanced Ages among African-Americans." Soc Sci Med 47(9):1231-1246.

Priest, N.K., B. Mackowiak, and D.E.L. Promislow. 2002. “The Role of Parental Age Effects on the Evolution of Aging.” Evolution 56(5):927-935.

Robine, J.-M., A. Cournil, N. Henon, and M. Allard. 2003. “Have Centenarians Had Younger Parents than the Others?” Experimental Gerontology 38(4):361-365.

Rocca, W.A., C.M. Van Duijn, D. Clayton et al. 1991. “Maternal Age and Alzheimer’s Disease: A Collaborative Re-analysis of Case-Control Studies. EURODEM Risk Factors Research Group.” Int. J. Epidemiol. 20(Supplement 2):S21-27.

Scholl, T.O., M.L. Hediger, J. Huang, F.E. Johnson, W. Smith, and I.G. Ances. 1992. "Young Maternal Age and Parity. Influences on Pregnancy Outcome.” Ann Epidemiol 2(5):565-575. 
Smith, K.R., G.P. Mineau, G. Garibotti, and R. Kerber. 2009. “Effects of Childhood and Middle-adulthood Family Conditions on Later-life Mortality: Evidence from the Utah Population Database, 1850-2002.” Social Science \& Medicine 68(9):1649-1658.

Strand, B.H. and A. Kunst. 2007. "Childhood Socioeconomic Position and Cause-specific Mortality in Early Adulthood." Am. J. Epidemiol. 165(1):85-93.

Tarin, J.J., J. Brines, and A. Cano. 1998. “Long-term Effects of Delayed Parenthood.” Hum. Reprod. 13(9):2371-2376.

Tymicki, K. 2009. “The Correlates of Infant and Childhood Mortality: A Theoretical Overview and New Evidence from the Analysis of Longitudinal Data of the Bejsce (Poland) Parish Register Reconstitution Study of the 18th-20th Centuries.” Demographic Research 20(23):559-594.

Van Noord-Zaadstra, B.M., C.W. Looman, H. Alsbach, J.D. Habbema, E.R. te Velde, and J. Karbaat. 1991. "Delaying Childbearing: Effect of Age on Fecundity and Outcome of Pregnancy.” BMJ 302(6789):1361-1365.

van Poppel, F. 2000. "Children in One-Parent Families: Survival as an Indicator of the Role of the Parents." Journal of Family History 25(3):269-290.

Westendorp, R.G.J. and T.B.L. Kirkwood. 2001. "Maternal and Paternal Lines of Familial Longevity." Population: An English Selection 13(1):223-235.

Yip B.H., Y. Pawitan and K. Czene. 2006. "Parental Age and Risk of Childhood Cancers: A Population-based Cohort Study from Sweden.” Int. J. Epidemiol. 2006, 35(6):1495-1503. 
Tables

TABLE 1. Baseline Demographic and Health Characteristics (Means and Standard Deviations) by Maternal Age. Health and Retirement Study, Participants aged 40 or More at Baseline.

\begin{tabular}{|c|c|c|c|c|c|c|c|}
\hline & \multicolumn{7}{|c|}{ Maternal age } \\
\hline & Overall & 14-19 & $20-24$ & $25-34$ & $35-39$ & $40-44$ & $45-49$ \\
\hline \multicolumn{8}{|l|}{ Demographic characteristics } \\
\hline Number of respondents (\%) & $\begin{array}{r}18,335 \\
(100)\end{array}$ & $\begin{array}{l}3,046 \\
(16.6)\end{array}$ & $\begin{array}{l}5,481 \\
(29.9)\end{array}$ & $\begin{array}{l}7,598 \\
(41.4)\end{array}$ & $\begin{array}{r}1,521 \\
(8.3)\end{array}$ & $\begin{array}{r}544 \\
(3.0)\end{array}$ & $\begin{array}{r}145 \\
(0.8)\end{array}$ \\
\hline Birth year (SD) & $\begin{array}{r}1939.6 \\
(8.4)\end{array}$ & $\begin{array}{r}1939.3 \\
(8.6)\end{array}$ & $\begin{array}{r}1939.7 \\
(8.6)\end{array}$ & $\begin{array}{r}1939.8 \\
(8.3)\end{array}$ & $\begin{array}{r}1939.4 \\
(8.1)\end{array}$ & $\begin{array}{r}1938.6 \\
(8.0)\end{array}$ & $\begin{array}{r}1937.7 \\
(7.9)\end{array}$ \\
\hline Age at first interview (SD) & $\begin{array}{l}56.3 \\
(6.7)\end{array}$ & $\begin{array}{l}56.4 \\
(7.0)\end{array}$ & $\begin{array}{l}56.4 \\
(6.8)\end{array}$ & $\begin{array}{l}56.1 \\
(6.5)\end{array}$ & $\begin{array}{l}56.2 \\
(6.5)\end{array}$ & $\begin{array}{l}57.1 \\
(6.7)\end{array}$ & $\begin{array}{l}57.3 \\
(6.9)\end{array}$ \\
\hline Women, \% & 59.4 & 58.3 & 59.9 & 59.5 & 59.9 & 59.0 & 49.0 \\
\hline \multicolumn{8}{|l|}{ Race/Ethnicity, \% } \\
\hline White & 81.0 & 71.8 & 82.1 & 84.1 & 81.5 & 80.0 & 64.1 \\
\hline African American & 15.3 & 24.3 & 14.2 & 12.5 & 14.6 & 14.0 & 28.3 \\
\hline Other & 3.7 & 3.9 & 3.7 & 3.4 & 3.9 & 6.1 & 7.6 \\
\hline \multicolumn{8}{|l|}{ Dependent variables } \\
\hline Died during the follow-up, $\%$ & 17.1 & 19.3 & 17.2 & 15.6 & 18.3 & 18.9 & 29.7 \\
\hline \multicolumn{8}{|l|}{ Mean follow-up, years (SD) } \\
\hline For those who died & $8.2(4.4)$ & $8.0(4.4)$ & $8.4(4.5)$ & $8.1(4.3)$ & $8.4(4.5)$ & $8.1(4.1)$ & $9.0(4.2)$ \\
\hline For censored & $11.8(5.0)$ & $11.9(4.9)$ & $11.6(5.0)$ & $11.7(5.0)$ & $12.0(4.9)$ & $12.0(4.8)$ & $12.5(4.7)$ \\
\hline Frailty index** (SD) & $1.1(1.2)$ & $1.2(1.2)$ & $1.1(1.2)$ & $1.0(1.1)$ & $1.2(1.2)$ & $1.2(1.3)$ & $1.4(1.3)$ \\
\hline Self-rated health* (SD) & $2.6(1.2)$ & $2.7(1.2)$ & $2.6(1.2)$ & $2.5(1.2)$ & $2.7(1.2)$ & $2.7(1.3)$ & $3.1(1.2)$ \\
\hline Height, centimeters (SD) & $\begin{array}{l}168.9 \\
(10.1)\end{array}$ & $\begin{array}{l}168.5 \\
(10.2)\end{array}$ & $\begin{array}{l}168.8 \\
(10.0)\end{array}$ & $\begin{array}{l}169.3 \\
(10.0)\end{array}$ & $\begin{array}{l}168.7 \\
(10.0)\end{array}$ & $\begin{array}{l}168.5 \\
(10.3)\end{array}$ & $\begin{array}{l}169.2 \\
(10.0)\end{array}$ \\
\hline Obese (BMI >= 30), \% & 25.5 & 30.1 & 25.4 & 23.5 & 26.4 & 25.9 & 26.9 \\
\hline \multicolumn{8}{|l|}{ Independent variables } \\
\hline Mother's educ. 8+ years, \% & 69.7 & 68.0 & 72.9 & 71.9 & 58.6 & 54.6 & 37.9 \\
\hline Mother alive when ego $40, \%$ & 79.1 & 87.3 & 87.8 & 78.2 & 60.0 & 47.8 & 25.5 \\
\hline $\begin{array}{l}\text { Own household income, \$ } \\
\text { (SD) }\end{array}$ & $\begin{array}{r}56702 \\
(96036)\end{array}$ & $\begin{array}{r}46581 \\
(77686)\end{array}$ & $\begin{array}{r}57505 \\
(78136)\end{array}$ & $\begin{array}{r}61987 \\
(120286)\end{array}$ & $\begin{array}{r}52581 \\
(56805)\end{array}$ & $\begin{array}{r}48692 \\
(55201)\end{array}$ & $\begin{array}{r}35242 \\
(29552)\end{array}$ \\
\hline \multicolumn{8}{|l|}{ Own education, \% } \\
\hline Less than high school & 22.5 & 28.0 & 21.2 & 20.3 & 23.6 & 27.6 & 44.1 \\
\hline High school & 53.4 & 55.1 & 55.0 & 52.0 & 52.7 & 50.9 & 44.8 \\
\hline Some college & 15.9 & 11.9 & 16.1 & 17.9 & 15.1 & 14.5 & 6.2 \\
\hline BA or higher & 8.2 & 5.1 & 7.8 & 9.9 & 8.7 & 7.0 & 4.8 \\
\hline
\end{tabular}

* Coded as a linear variable with range from $1=$ Excellent to $5=$ Poor

** Frailty index calculated as the sum of the following eight diagnosed medical conditions: cancer, lung disease, mental health problems, diabetes, heart disease, stroke, blood pressure, and arthritis. 
TABLE 2: Maternal age and frailty index. Negative binomial model; frailty index calculated as the sum of eight diagnosed medical conditions (cancer, lung disease, mental health problems, diabetes, heart disease, stroke, blood pressure, and arthritis). Data: Health and Retirement Study.

\begin{tabular}{|c|c|c|c|c|c|}
\hline & Model 1 & Model 2 & Model 3 & Model 4 & Model 5 \\
\hline \multicolumn{6}{|l|}{ Maternal age } \\
\hline $14-19$ & $0.131^{* * *}$ & $0.130^{* * *}$ & $0.149^{* * *}$ & $0.147^{* * *}$ & $0.109^{* * *}$ \\
\hline $20-24$ & $0.036^{*}$ & $0.038^{*}$ & $0.050^{* *}$ & $0.051^{* *}$ & $0.038^{*}$ \\
\hline 25-34 (ref) & 0 & 0 & 0 & 0 & 0 \\
\hline $35-39$ & $0.093^{* * *}$ & $0.076^{* *}$ & $0.064^{*}$ & 0.050 & 0.051 \\
\hline $40-44$ & $0.108^{*}$ & $0.088^{*}$ & 0.058 & 0.043 & 0.034 \\
\hline $45-49$ & $0.223^{* *}$ & $0.187^{*}$ & $0.145 \wedge \mathrm{t}$ & 0.117 & 0.076 \\
\hline Birth year & $0.011^{* * *}$ & $0.012^{* * *}$ & $0.012^{* * *}$ & $0.013^{* * *}$ & $0.017^{* * *}$ \\
\hline Age at first interview & $0.142^{* * *}$ & $0.141^{* * *}$ & $0.142^{* * *}$ & $0.141^{* * *}$ & $0.139^{* * *}$ \\
\hline Age $^{\wedge} 2$ at first interview / 100 & $-0.083^{* * *}$ & $-0.083^{* * *}$ & $-0.082^{* * *}$ & $-0.082^{* * *}$ & $-0.078^{* * *}$ \\
\hline Female & $0.095^{* * *}$ & $0.092^{* * *}$ & $0.092^{* * *}$ & $0.089^{* * *}$ & $0.067^{* * *}$ \\
\hline \multicolumn{6}{|l|}{ Race/ethnicity (ref: White) } \\
\hline African American & $0.268^{* * *}$ & $0.242^{* * *}$ & $0.253^{* * *}$ & $0.230^{* * *}$ & $0.179^{* * *}$ \\
\hline Other & $0.092^{*}$ & 0.045 & $0.085^{*}$ & 0.042 & 0.012 \\
\hline \multicolumn{6}{|l|}{ Maternal characteristics } \\
\hline Mother's education 8+ years & & $-0.129^{* * *}$ & & $-0.121^{* * *}$ & -0.010 \\
\hline Mother alive when ego 40 & & & $-0.158^{* * *}$ & $-0.149^{* * *}$ & $-0.132^{* * *}$ \\
\hline \multicolumn{6}{|l|}{ Education (ref: High school) } \\
\hline None & & & & & $0.144^{* * *}$ \\
\hline College & & & & & $-0.142^{* * *}$ \\
\hline BA or above & & & & & $-0.241^{* * *}$ \\
\hline Household income (log) & & & & & $-0.057^{* * *}$ \\
\hline Constant & $-27.454^{* * *}$ & $-28.955^{* * *}$ & $-28.859^{* * *}$ & $-30.170^{* * *}$ & $-38.379^{* * *}$ \\
\hline Observations & 18335 & 18335 & 18335 & 18335 & 18335 \\
\hline AIC & 50603.21 & 50542.62 & 50532.16 & 50479.77 & 50060.40 \\
\hline $\mathrm{BIC}$ & 50704.83 & 50652.06 & 50641.59 & 50597.01 & 50208.91 \\
\hline Chi squared & 1096.01 & 1158.60 & 1169.06 & 1223.46 & 1650.82 \\
\hline Pseudo R squared & 0.02 & 0.02 & 0.02 & 0.02 & 0.03 \\
\hline
\end{tabular}

Model 1: Negative binomial model controlling for birth year, age, age squared, sex and race/ethnicity.

Model 2: Adds maternal education to Model 1.

Model 3: Adds lifespan overlap between the mother and the child to Model 1.

Model 4: Adds maternal education and lifespan overlap with the mother to Model 1.

Model 5: Adds controls for own education and household income to Model 4.

All models control for household clustering in the standard error estimation. 
TABLE 3: Maternal age and self-rated health. Linear model; self-rated health is coded as a linear response variable with $1=$ Excellent and 5 = Poor. Data: Health and Retirement Study.

\begin{tabular}{|c|c|c|c|c|c|}
\hline & Model 1 & Model 2 & Model 3 & Model 4 & Model 5 \\
\hline \multicolumn{6}{|l|}{ Maternal age } \\
\hline $14-19$ & $0.161^{* * *}$ & $0.155^{* * *}$ & $0.181^{* * *}$ & $0.172^{* * *}$ & $0.086^{* * *}$ \\
\hline $20-24$ & $0.048^{*}$ & $0.056^{* *}$ & $0.063^{* *}$ & $0.068^{* * *}$ & $0.040^{*}$ \\
\hline 25-34 (ref) & 0 & 0 & 0 & 0 & 0 \\
\hline $35-39$ & $0.136^{* * *}$ & $0.078^{*}$ & $0.101^{* *}$ & 0.051 & 0.057 \\
\hline $40-44$ & $0.149^{* *}$ & 0.078 & $0.090 \wedge \mathrm{t}$ & 0.031 & 0.012 \\
\hline $45-49$ & $0.441^{* * *}$ & $0.310^{* *}$ & $0.342^{* * *}$ & $0.231^{*}$ & 0.132 \\
\hline Birth year & $0.009^{* * *}$ & $0.012^{* * *}$ & $0.010^{* * *}$ & $0.012^{* * *}$ & $0.023^{* * *}$ \\
\hline Age at first interview & $0.073^{* * *}$ & $0.072^{* * *}$ & $0.072^{* * *}$ & $0.072^{* * *}$ & $0.067^{* * *}$ \\
\hline Age $^{\wedge} 2$ at first interview / 100 & $-0.037^{* *}$ & $-0.037^{* *}$ & $-0.036^{* *}$ & $-0.037^{* *}$ & $-0.029^{*}$ \\
\hline Female & 0.024 & 0.015 & 0.020 & 0.013 & $-0.032 \wedge t$ \\
\hline \multicolumn{6}{|l|}{ Race/ethnicity (ref: White) } \\
\hline African American & $0.519^{* * *}$ & $0.429^{* * *}$ & $0.501^{* * *}$ & $0.416^{* * *}$ & $0.291^{* * *}$ \\
\hline Other & $0.473^{* * *}$ & $0.306^{* * *}$ & $0.466^{* * *}$ & $0.303^{* * *}$ & $\begin{array}{l}0.240^{* * *} \\
21 \%\end{array}$ \\
\hline \multicolumn{6}{|l|}{ Maternal characteristics } \\
\hline Mother's education 8+ years & & $-0.468^{* * *}$ & & $-0.459^{* * *}$ & $-0.180^{* * *}$ \\
\hline Mother alive when ego 40 & & & $-0.196^{* * *}$ & $-0.161^{* * *}$ & $-0.120^{* * *}$ \\
\hline \multicolumn{6}{|l|}{ Education (ref: High school) } \\
\hline None & & & & & $0.440^{* * *}$ \\
\hline College & & & & & $-0.270^{* * *}$ \\
\hline BA or above & & & & & $-0.366^{* * *}$ \\
\hline Household income (log) & & & & & $-0.142^{* * *}$ \\
\hline Constant & $-17.793^{* * *}$ & $-22.808^{* * *}$ & $-19.301^{* * *}$ & $-23.944^{* * *}$ & $-43.548^{* * *}$ \\
\hline Observations & 18335 & 18335 & 18335 & 18335 & 18335 \\
\hline AIC & 57494.11 & 56898.97 & 57415.97 & 56845.38 & 55078.29 \\
\hline $\mathrm{BIC}$ & 57587.91 & 57000.58 & 57517.58 & 56954.81 & 55218.99 \\
\hline F statistic & 80.64 & 126.91 & 80.93 & 121.77 & 212.09 \\
\hline R squared & 0.05 & 0.08 & 0.05 & 0.08 & 0.16 \\
\hline R squared, adjusted & 0.05 & 0.08 & 0.05 & 0.08 & 0.16 \\
\hline
\end{tabular}

Model 1: Linear model controlling for birth year, age, age squared, sex and race/ethnicity.

Model 2: Adds maternal education to Model 1.

Model 3: Adds lifespan overlap between the mother and the child to Model 1.

Model 4: Adds maternal education and lifespan overlap with the mother to Model 1.

Model 5: Adds controls for own education and household income to Model 4.

All models control for household clustering in the standard error estimation. 
TABLE 4: Maternal age and height. Linear model; height is measured in centimeters. Data: Health and Retirement Study.

\begin{tabular}{|c|c|c|c|c|c|}
\hline & Model 1 & Model 2 & Model 3 & Model 4 & Model 5 \\
\hline \multicolumn{6}{|l|}{ Maternal age } \\
\hline $14-19$ & $-0.889^{* * *}$ & $-0.864^{* * *}$ & $-0.941^{* * *}$ & $-0.901^{* * *}$ & $-0.702^{* * *}$ \\
\hline $20-24$ & $-0.338^{* *}$ & $-0.373^{* *}$ & $-0.378^{* *}$ & $-0.399^{* *}$ & $-0.336^{* *}$ \\
\hline 25-34 (ref) & 0 & 0 & 0 & 0 & 0 \\
\hline $35-39$ & $-0.459^{*}$ & -0.197 & $-0.368 \wedge \mathrm{t}$ & -0.137 & -0.166 \\
\hline $40-44$ & $-0.604 \wedge \mathrm{t}$ & -0.286 & -0.452 & -0.185 & -0.156 \\
\hline $45-49$ & $-1.405^{* *}$ & -0.814 & $-1.148^{\wedge} \mathrm{t}$ & -0.643 & -0.408 \\
\hline Birth year & $0.027^{*}$ & 0.014 & $0.025^{*}$ & 0.013 & -0.013 \\
\hline Age at first interview & 0.102 & 0.104 & 0.102 & 0.105 & 0.101 \\
\hline Age $^{\wedge} 2$ at first interview / 100 & -0.124 & -0.122 & -0.126 & -0.124 & $-0.132 \wedge t$ \\
\hline Female & $-14.608^{* * *}$ & $-14.568^{* * *}$ & $-14.598^{* * *}$ & $-14.562^{* * *}$ & $-14.493^{* * *}$ \\
\hline \multicolumn{6}{|l|}{ Race/ethnicity (ref: White) } \\
\hline African American & $0.531^{* * *}$ & $0.940^{* * *}$ & $0.578^{* * *}$ & $0.968^{* * *}$ & $1.251^{* * *}$ \\
\hline Other & $-4.612^{* * *}$ & $-3.856^{* * *}$ & $-4.593^{* * *}$ & $-3.851^{* * *}$ & $-3.703^{* * *}$ \\
\hline \multicolumn{6}{|l|}{ Maternal characteristics } \\
\hline Mother's education 8+ years & & $2.110^{* * *}$ & & $2.089^{* * *}$ & $1.340^{* * *}$ \\
\hline Mother alive when ego 40 & & & $0.508^{* * *}$ & $0.349^{* *}$ & $0.272^{*}$ \\
\hline \multicolumn{6}{|l|}{ Education (ref: High school) } \\
\hline None & & & & & $-1.612^{* * *}$ \\
\hline College & & & & & $0.582^{* * *}$ \\
\hline BA or above & & & & & $0.837^{* * *}$ \\
\hline Household income (log) & & & & & $0.200^{* * *}$ \\
\hline Constant & $123.781^{* * *}$ & $146.375^{* * *}$ & $127.690^{* * *}$ & $148.836^{* * *}$ & $197.899^{* * *}$ \\
\hline Observations & 18335 & 18335 & 18335 & 18335 & 18335 \\
\hline AIC & 123427.81 & 123099.65 & 123415.07 & 123094.61 & 122826.48 \\
\hline $\mathrm{BIC}$ & 123521.61 & 123201.27 & 123516.69 & 123204.04 & 122967.17 \\
\hline F statistic & 1769.55 & 1679.22 & 1624.53 & 1551.10 & 1220.22 \\
\hline R squared & 0.52 & 0.52 & 0.52 & 0.52 & 0.53 \\
\hline R squared, adjusted & 0.51 & 0.52 & 0.52 & 0.52 & 0.53 \\
\hline
\end{tabular}

${ }^{\mathrm{t}} p<.10,{ }^{*} p<.05,{ }^{* *} p<.01,{ }^{* * *} p<.001$

Model 1: Linear model controlling for birth year, age, age squared, sex and race/ethnicity.

Model 2: Adds maternal education to Model 1.

Model 3: Adds lifespan overlap between the mother and the child to Model 1.

Model 4: Adds maternal education and lifespan overlap with the mother to Model 1.

Model 5: Adds controls for own education and household income to Model 4.

All models control for household clustering in the standard error estimation. 
TABLE 5: Maternal age and odds ratio for obesity. Logistic model; obesity is defined as body mass index BMI (kg/m2) 30 or above. Data: Health and Retirement Study.

\begin{tabular}{|c|c|c|c|c|c|}
\hline & Model 1 & Model 2 & Model 3 & Model 4 & Model 5 \\
\hline \multicolumn{6}{|l|}{ Maternal age } \\
\hline 14-19 & $1.330^{* * *}$ & $1.328^{* * *}$ & $1.355^{* * *}$ & $1.351^{* * *}$ & $1.295^{* * *}$ \\
\hline $20-24$ & $1.099^{*}$ & $1.103^{*}$ & $1.115^{* *}$ & $1.117^{* *}$ & $1.100^{*}$ \\
\hline 25-34 (ref) & 1 & 1 & 1 & 1 & 1 \\
\hline $35-39$ & $1.167^{*}$ & $1.138^{*}$ & $1.132 \wedge t$ & 1.109 & 1.112 \\
\hline $40-44$ & 1.161 & 1.126 & 1.104 & 1.078 & 1.068 \\
\hline $45-49$ & 1.171 & 1.109 & 1.075 & 1.029 & 0.988 \\
\hline Birth year & $1.034^{* * *}$ & $1.035^{* * *}$ & $1.035^{* * *}$ & $1.036^{* * *}$ & $1.041^{* * *}$ \\
\hline Age at first interview & $1.110^{* *}$ & $1.110^{* *}$ & $1.110^{* *}$ & $1.110^{* *}$ & $1.109^{* *}$ \\
\hline Age $^{\wedge} 2$ at first interview / 100 & $0.929^{* *}$ & $0.929^{* *}$ & $0.929^{* *}$ & $0.929^{* *}$ & $0.932^{*}$ \\
\hline Female & $1.299^{* * *}$ & $1.295^{* * *}$ & $1.294^{* * *}$ & $1.291^{* * *}$ & $1.261^{* * *}$ \\
\hline \multicolumn{6}{|l|}{ Race/ethnicity (ref: White) } \\
\hline African American & $1.831^{* * *}$ & $1.764^{* * *}$ & $1.804^{* * *}$ & $1.744^{* * *}$ & $1.663^{* * *}$ \\
\hline Other & 0.989 & 0.921 & 0.983 & 0.919 & 0.900 \\
\hline \multicolumn{6}{|l|}{ Maternal characteristics } \\
\hline Mother's education 8+ years & & $0.822^{* * *}$ & & $0.830^{* * *}$ & 0.937 \\
\hline Mother alive when ego 40 & & & $0.843^{* * *}$ & $0.855^{* * *}$ & $0.871^{* *}$ \\
\hline \multicolumn{6}{|l|}{ Education (ref: High school) } \\
\hline None & & & & & $1.143^{* *}$ \\
\hline College & & & & & $0.841^{* * *}$ \\
\hline BA or above & & & & & $0.703^{* * *}$ \\
\hline Household income (log) & & & & & $0.944^{* * *}$ \\
\hline Observations & 18335 & 18335 & 18335 & 18335 & 18335 \\
\hline AIC & 20407.22 & 20383.13 & 20393.61 & 20372.08 & 20285.95 \\
\hline $\mathrm{BIC}$ & 20501.02 & 20484.75 & 20495.23 & 20481.51 & 20426.65 \\
\hline Log likelihood & -10191.61 & -10178.57 & -10183.81 & -10172.04 & -10124.97 \\
\hline LR chi squared & 439.98 & 466.07 & 455.59 & 479.12 & 573.25 \\
\hline R squared, pseudo & 0.02 & 0.02 & 0.02 & 0.02 & 0.03 \\
\hline
\end{tabular}

${ }^{\mathrm{t}} p<.10,{ }^{*} p<.05,{ }^{* *} p<.01,{ }^{* * *} p<.001$

Model 1: Logistic model controlling for birth year, age, age squared, sex and race/ethnicity.

Model 2: Adds maternal education to Model 1.

Model 3: Adds lifespan overlap between the mother and the child to Model 1.

Model 4: Adds maternal education and lifespan overlap with the mother to Model 1.

Model 5: Adds controls for own education and household income to Model 4.

All models control for household clustering in the standard error estimation. 
TABLE 6: Maternal age and all-cause mortality hazard ratio (HR). Mortality hazard ratios are estimated using the Cox proportional hazard model. Follow-up is from first interview to last interview (year 2008) or death. Data: Health and Retirement Study

\begin{tabular}{|c|c|c|c|c|c|}
\hline & Model 1 & Model 2 & Model 3 & Model 4 & Model 5 \\
\hline \multicolumn{6}{|l|}{ Maternal age } \\
\hline 14-19 & $1.132^{*}$ & $1.130^{*}$ & $1.169^{* *}$ & $1.164^{* *}$ & $1.102^{\wedge} \mathrm{t}$ \\
\hline $20-24$ & 1.072 & $1.077 \wedge \mathrm{t}$ & $1.097^{*}$ & $1.100^{*}$ & $1.079 \wedge \mathrm{t}$ \\
\hline 25-34 (ref) & 1 & 1 & 1 & 1 & 1 \\
\hline $35-39$ & $1.143^{*}$ & 1.109 & 1.094 & 1.067 & 1.062 \\
\hline $40-44$ & 1.114 & 1.080 & 1.027 & 1.006 & 0.989 \\
\hline $45-49$ & $1.538^{* *}$ & $1.431^{*}$ & $1.377^{*}$ & $1.298 \wedge \mathrm{t}$ & 1.216 \\
\hline Birth year & $0.909^{* * *}$ & $0.910^{* * *}$ & $0.910^{* * *}$ & $0.911^{* * *}$ & $0.918^{* * *}$ \\
\hline Age at first interview & 1.027 & 1.027 & 1.026 & 1.026 & 1.030 \\
\hline Age $^{\wedge} 2$ at first interview / 100 & 0.971 & 0.970 & 0.972 & 0.972 & 0.972 \\
\hline Female & $0.618^{* * *}$ & $0.615^{* * *}$ & $0.616^{* * *}$ & $0.613^{* * *}$ & $0.585^{* * *}$ \\
\hline \multicolumn{6}{|l|}{ Race/ethnicity (ref: White) } \\
\hline African American & $1.565^{* * *}$ & $1.493^{* * *}$ & $1.525^{* * *}$ & $1.462^{* * *}$ & $1.337^{* * *}$ \\
\hline Other & $1.400^{* * *}$ & $1.286^{*}$ & $1.374^{* *}$ & $1.270^{*}$ & $1.198 \wedge t$ \\
\hline \multicolumn{6}{|l|}{ Maternal characteristics } \\
\hline Mother’s education 8+ years & & $0.796^{* * *}$ & & $0.807^{* * *}$ & 0.958 \\
\hline Mother alive when ego 40 & & & $0.791^{* * *}$ & $0.805^{* * *}$ & $0.829^{* * *}$ \\
\hline \multicolumn{6}{|l|}{ Education (ref: High school) } \\
\hline None & & & & & $1.255^{* * *}$ \\
\hline College & & & & & $0.781^{* * *}$ \\
\hline BA or above & & & & & $0.622^{* * *}$ \\
\hline Household income (log) & & & & & $0.913^{* * *}$ \\
\hline Observations & 18335 & 18335 & 18335 & 18335 & 18335 \\
\hline AIC & 58026.93 & 57993.44 & 57999.69 & 57970.32 & 57768.46 \\
\hline $\mathrm{BIC}$ & 58112.91 & 58087.24 & 58093.49 & 58071.94 & 57901.35 \\
\hline Log likelihood & -29002.47 & -28984.72 & -28987.85 & -28972.16 & -28867.23 \\
\hline LR chi squared & 1466.92 & 1502.41 & 1496.16 & 1527.53 & 1737.39 \\
\hline
\end{tabular}

Model 1: Cox Proportional Hazards model controlling for birth year, age, age squared, sex and race/ethnicity.

Model 2: Adds maternal education to Model 1.

Model 3: Adds lifespan overlap between the mother and the child to Model 1.

Model 4: Adds maternal education and lifespan overlap with the mother to Model 1.

Model 5: Adds controls for own education and household income to Model 4.

All models control for household clustering in the standard error estimation. 
Figure 1. Maternal age and frailty index (Panel A), self-rated health (Panel B), height (Panel C) obesity (panel D) and mortality (Panel E). Estimates are based on a semiparametric lowess model. Solid line corresponds to Model 1 and controls for only demographic characteristics birth year, age, age squared, sex and race/ethnicity. Dashed line corresponds to Model 4 and adds as controls maternal education and lifespan overlap with the child and the mother.
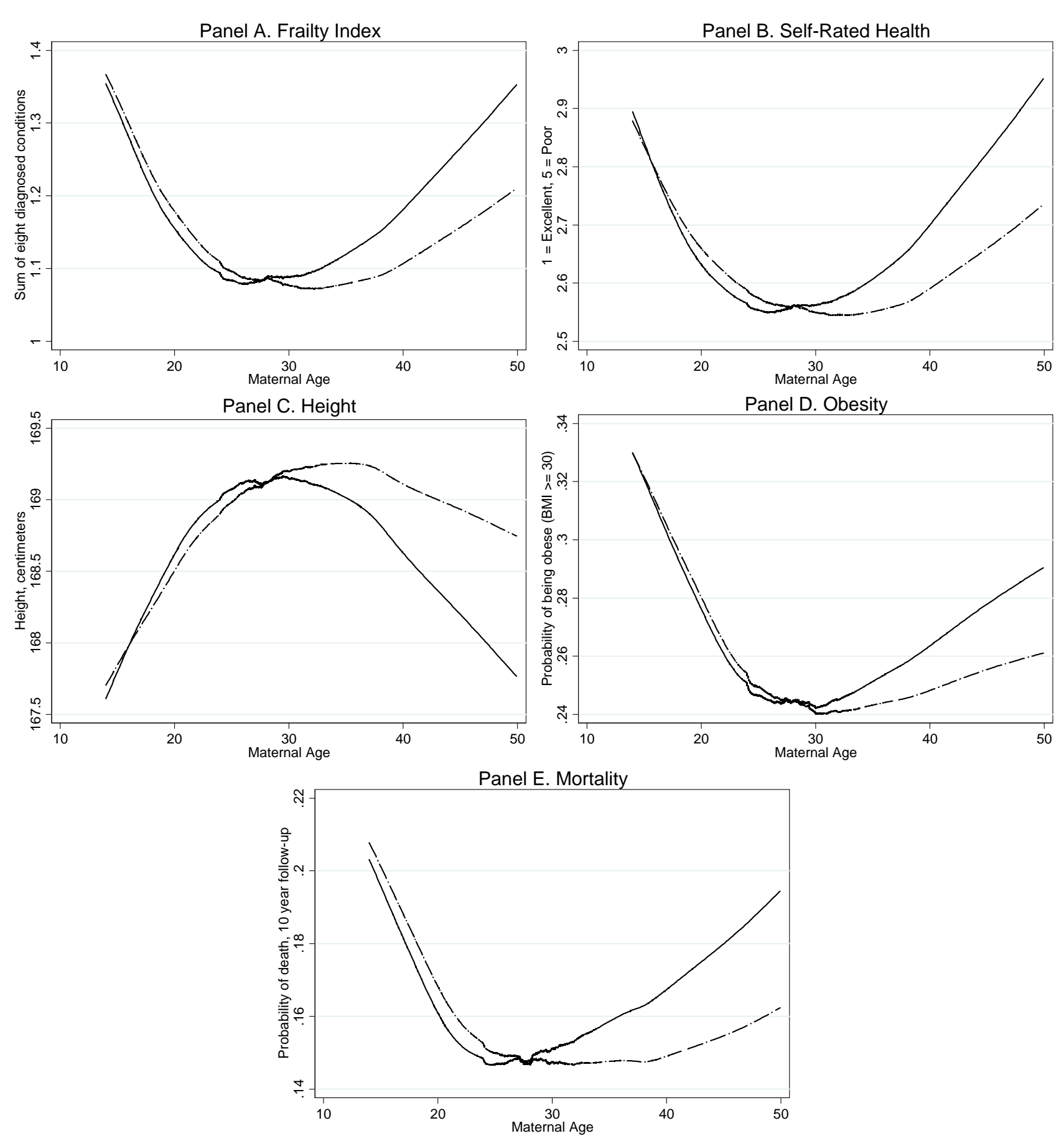

- Model 1: Controls for birth year, age, age squared, sex, and race/ethnicity

- . - Model 4: Add controls for maternal education and lifespan overlap between the child and the mother 